\title{
SD. 03. Sleep quality and depressive symptoms before and after bariatric surgery
}

\author{
PINTO, T.F. ${ }^{1}$, BRUIN, P.F.C. ${ }^{2}$, LEMOS, F.N. ${ }^{3}$ \\ ${ }^{1}$ Pharmaceutical Sciences Postgraduate Program \\ 2 Department of Medicine, Federal University of Ceará \\ ${ }^{3}$ Dr. César Cals General Hospital, Fortaleza, Brazil
}

Introduction: Sleep deprivation can lead to hormonal and metabolic changes that favor fat accumulation and weight gain. Obesity, in turn, may reduce sleep quality and contribute to sleep loss. Depressive symptoms have been frequently reported in obesity surgery candidates and may be associated with poor sleep in these patients. The purpose of this study was to evaluate the impact of bariatric surgery on sleep quality and depressive symptoms in obese subjects. Methods: In fifteen morbidly obese patients, subjective sleep quality was assessed by the Pittsburgh Sleep Quality Index (PSQI), risk for obstructive sleep apnea by the Berlin Questionnaire (BQ) and depressive symptoms by the Beck Depression Inventory short form (BDI) before and six to twelve months after bariatric surgery. Results: Preliminary data show an improvement in sleep quality after surgery, as demonstrated by a significant reduction in PSQI scores $[2.60( \pm 1.72)$ vs $5.27( \pm 3.88)$; $p=0.05$; paired $t$ test]. High risk for obstructive sleep apnea was found in $67 \%$ of the patients preoperatively and in only $6 \%$ after surgery. On average, depressive symptoms, as assessed by the BDI, were significantly improved after surgery [3.56 ( \pm 4.19$)$ vs $8.67( \pm$ $6.15 ; p=0.02$; paired $t$ test]. Before surgery, $73 \%$ of the patients presented moderate/ severe depressive symptoms $(\mathrm{BDI}>15)$ as compared to $20 \%$ after bariatric surgery. Conclusions: Poor sleep quality and depressive symptoms are common in morbidly obese patients and can be significantly improved by bariatric surgery.

Keywords: Sleep Quality, Depressive Symptoms, Bariatric Surgery

PINTO, T.F.; BRUIN, P.F.C.; LEMOS, F.N. 2013. Sleep quality and depressive symptoms before and after bariatric surgery, p.30. In: Oriá, Reinaldo Barreto; Andrade, Geanne Matos de; Bruin, Veralice Meireles S. de. I International Symposium in Neuroscience Meeting [Blucher Neuroscience Proceedings n.1 v.1]. São Paulo: Blucher, 2014 http://dx.doi.org/10.5151/isnm-sine25

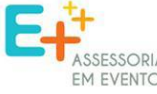

